\title{
MODEL ARSITEKTUR NEURAL NETWORK DENGAN BACKPROPOGATION PADA PREDIKSI TOTAL LABA RUGI KOMPREHENSIF BANK UMUM KONVENSIONAL
}

\author{
Agus Perdana Windarto' ${ }^{1}$, Muhammad Ridwan Lubis ${ }^{2}$, Solikhun ${ }^{3}$ \\ 1 Program Studi Sistem Informasi, STIKOM Tunas Bangsa Pematangsiantar \\ 2Program Studi Komputerisasi Akuntansi, AMIK Tunas Bangsa Pematangsiantar \\ 2Program Studi Manajemen Informatika, AMIK Tunas Bangsa Pematangsiantar \\ Email: ${ }^{1}$ agus.perdana@amiktunasbangsa.ac.id, \\ 2m.ridwanlubis@amiktunasbangsa.ac.id, 3solikhun@amiktunasbangsa.ac.id
}

\begin{abstract}
The total comprehensive income prediction is very important to predict where the total number of comprehensive income is in a bank. This information is useful for the public in determining the direction of public investment in the future, as well as for banks to determine the marketing strategy in increasing the total comprehensive income. This study aims to create the best architectural model using Backpropogation where this model can later be made to make predictions of total comprehensive income. The variable used in this study is the total comprehensive income statement data of PT. Bank Mandiri, Tbk (January November 2016). Data sourced from the Financial Services Authority (www.ojk.go.id). From a series of trials conducted with 4 architectural models tested, namely 4-25-1; 4-50-1; 4-1001 and 4-50-75-1, obtained the best architectural model 4-50-1 with Epoch training = 1977, Mean Square Error (MSE) of 0,000997867 with the correctness of testing accuracy reaching $80 \%$.
\end{abstract}

Keywords: Artificial Neural Network, Back-propagation, Comprehensive Income, Prediction, Economy, Architecture

\begin{abstract}
Abstrak
Prediksi total laba rugi komprehensif sangatlah penting untuk memprediksi dimana posisi angka total laba rugi komprehensif pada suatu bank. Informasi tersebut berguna bagi masayarkat dalam menentukan arah investasi masyarakat ke depan, begitu juga bagi pihak bank berguna untuk menentukan kebijakan strategi pemasaran dalam meninggkatkan total laba komprehensif tersebut. Penelitian ini bertujuan untuk membuat model arsitektur terbaik dengan menggunakan Backpropogation dimana model ini nantinya dapat dilakukan untuk membuat prediksi terhadap total laba rugi komprehensif. Variabel yang digunakan pada penelitian ini adalah data total laba rugi komprehensif PT. Bank Mandiri,Tbk (Januari - November 2016). Data bersumber dari Otoritas Jasa Keuangan (www.ojk.go.id). Dari serangkaian uji coba yang dilakukan dengan 4 model arsitektur yang diuji yakni 4-25-1; 450-1; 4-100-1 dan 4-50-75-1, diperoleh model arsitektur terbaik 4-50-1 dengan Epoch training $=1977$, Mean Square Error (MSE) sebesar 0,000997867 dengan tingkat akurasi pengujian mencapai kebenaran $80 \%$.
\end{abstract}

Kata kunci: Jaringan saraf tiruan, Back-propagation, Laba Rugi Komprehensif, Prediksi, Ekonomi, Arsitektur 


\section{PENDAHULUAN}

Informasi laporan keuangan merupakan unsur penting bagi investor, kreditor dan pelaku bisnis lainnya. Informasi yang dihasilkan laporan keuangan akan sangat bermanfaat bagi pengguna laporan keuangan apabila informasi tersebut relevan dan bermanfaat untuk pengambilan keputusan. Informasi yang tersaji dalam laporan keuangan pada hakekatnya menyajikan keterangan, catatan atau gambaran baik untuk keadaan masa lalu. Laporan keuangan merupakan catatan mengenai informasi keuangan suatu perusahaan pada suatu periode akuntansi yang dapat digunakan untuk menggambarkan kinerja suatu perusahaan. Laporan keuangan perusahaan terdiri dari beberapa komponen, salah satunya laporan laba rugi. Pada dasarnya tujuan pelaporan laba rugi yaitu menilai kinerja perusahaan, hal tersebut dapat dilihat dari jumlah laba atau rugi yang diperoleh oleh perusahaan [1].

Dalam rangka mendorong laju pertumbuhan ekonomi menjadi lebih tinggi, Pemerintah sangat membutuhkan dukungan dari seluruh sektor atau bidang yang dapat menambah income atau pendapatan pemerintah. Jika pengeluaran lebih besar dari pendapatan maka pemerintah akan mengalami defisit dan sulit dalam menjalankan roda kepemerintahan dengan baik. Salah satu pendapat yang penting adalah dari sektor perbankan. Salah satu instrumen dari keberhasilan suatu perbankan adalah total laba rugi komprehensif. Perbankan harus bisa melakukan prediksi total laba rugi komprehensif kedepan agar pihak bank dapat mengambil langkah atau kebijakan bagaimana membuat strategi-strategi yang handal dalam upaya meningkatkan penghasilan komprehensif ke depan. Begitu juga bagi masyarakat, mereka akan bisa menentukan arah investasi kedepan. Prediksi total laba rugi komprehensif ke depan ditentukan berdasarkan data total laba rugi komprehensif sebelumnya dimulai dari bulan Januari 2016 sampai November 2016. Berikut data total laba rugi komprehensif bulan Januari sampai November 2016.

\begin{tabular}{|c|c|c|}
\hline No & Bulan & $\begin{array}{c}\text { Total Laba Rugi Komprehensif } \\
\text { Komprehensif }\end{array}$ \\
\hline 1 & Januari & $\mathrm{Rp} \quad 1.351 .543 .000 .000$ \\
\hline 2 & Februari & 3.342 .356 .000 .000 \\
\hline 3 & Maret & 5.648 .466 .000 .000 \\
\hline 4 & April & 32.852 .188 .000 .000 \\
\hline 5 & Mei & 33.438.427.000.000 \\
\hline 6 & Juni & 33.446 .210 .000 .000 \\
\hline 7 & Juli & 35.490 .474 .000 .000 \\
\hline 8 & Agustus & 36.709 .507 .000 .000 \\
\hline 9 & September & 38.497.486.000.000 \\
\hline 10 & Oktober & 39.294.183.000.000 \\
\hline 11 & November & 38.903 .299 .000 .000 \\
\hline
\end{tabular}

(sumber : $\underline{\text { www.ojk.go.id) }}$

Dari tabel 1 diatas menunjukkan bahwa pada bulan Januari total laba rugi komprehensifnya berada diangka Rp. 1.351.543.000.000, kemudian di bulan 
Februari, dan Maret mengalami kenaikan sebesar Rp. 1.990.813.000.000 (Lebih besar dari bulan Januari) dan Rp. 2.306.110.000.000 (Lebih besar dari bulan Februari), pada bulan April mengalami kenaikan yang sangat tinggi yaitu diangka Rp. 27.203.722.000.000, pada bulan Mei mengalami penurunan yaitu diangka Rp 586.239.000.000, pada bulan Juni mengalami penurunan kembali pada angka Rp. 7.783.000.000 dan stabil kembali pada bulan Juli, Agustus dan September pada angka Rp. 2.044.264.000.000, Rp. 1.219.033.000.000 dan Rp. 1.787.979.000.000 mengalami penurunan kembali pada bulan Oktober pada angka Rp 796.697.000.000 dan pada bulan November mengalami kerugian pada angka Rp 390.884.000.000. berikut tabel total laba rugi komprehensif perbulan dapat dilihat pada tabel 2 .

\begin{tabular}{clll} 
Tabel 2. Total Laba Rugi Komprehensif PT. Bank Mandiri, Tbk Perbulan \\
\cline { 2 - 3 } No & Bulan & \multicolumn{3}{c}{$\begin{array}{c}\text { Total Laba Rugi Komprehensif } \\
\text { Komprehensif }\end{array}$} \\
\hline 1 & Januari & Rp. & 1.351 .543 .000 .000 \\
2 & Februari & $\mathrm{Rp}$ & 1.990 .813 .000 .000 \\
3 & Maret & $\mathrm{Rp}$ & 2.306 .110 .000 .000 \\
4 & April & $\mathrm{Rp}$ & 27.203 .722 .000 .000 \\
5 & Mei & $\mathrm{Rp}$ & 586.239 .000 .000 \\
6 & Juni & $\mathrm{Rp}$ & 7.783 .000 .000 \\
7 & Juli & $\mathrm{Rp}$ & 2.044 .264 .000 .000 \\
8 & Agustus & $\mathrm{Rp}$ & 1.219 .033 .000 .000 \\
9 & September & $\mathrm{Rp}$ & 1.787 .979 .000 .000 \\
10 & Oktober & $\mathrm{Rp}$ & 796.697 .000 .000 \\
11 & November & $\mathrm{Rp}$ & -390.884 .000 .000 \\
\hline
\end{tabular}

(sumber : $\underline{w} w w . o j k . g o . i d)$

Seiring dengan meningkatnya kesadaran berinvestasi, prediksi total laba rugi komprehensif tentu menjadi instrumen investasi yang banyak ditunggu masyarakat. Masyarakat akan dapat menentukan arah investasi kedepan begitu juga bagi pihak bank akan menjadi bahan pertimbangan dalam menentukan arah kebijakan ke depan agar dapat menentukan strategi kedepan untuk meningkatakan total laba rugi komprehensif demi kesehatan financial dari bank tersebut.

Banyak masyarakat pemula yang tidak dapat memiliki instrumen ini. Untuk mengatasi keadaan ini, perlu sebuah kajian yang dapat memprediksi total laba rugi komprehensif kedepannya dengan menggunakan sistem pendukung keputusan [1] yang nantinya dapat bermanfaat bagi masyarakat dan pihak bank. Dengan model ini diharapkan dapat menjadi masukan kepada pihak bank untuk meningkatkan total laba rugi komprehensif tiap bulannnya sehingga masa yang akan datang masyarakat dapat berinvestasi dengan baik sehingga dapat menyokong finansial dan mendorong laju pertumbuhan ekonomi pada sektor perbankan. 


\section{METODOLOGI PENELITIAN}

\subsection{Neural Network}

Neural Network adalah suatu metode komputasi yang meniru sistem jaringan saraf biologis[2]. Metode ini menggunakan elemen perhitungan non-linier dasar yang disebut neuron yang diorganisasikan sebagai jaringan yang saling berhubungan, sehingga mirip dengan jaringan saraf manusia. Layaknya neuron biologi, Jaringan saraf tiruan juga merupakan sistem yang bersifat "fault tolerant" dalam 2 hal. Pertama, dapat mengenali sinyal input yang agak berbeda dari yang pernah diterima sebelumnya. Sebagai contoh, manusia sering dapat mengenali seseorang yang wajahnya pernah dilihat dari foto atau dapat mengenali sesorang yang wajahnya agak berbeda karena sudah lama tidak menjumpainya. Kedua, tetap mampu bekerja meskipun beberapa neuronnya tidak mampu bekerja dengan baik. Jika sebuah neuron rusak, neuron lain dapat dilatih untuk menggantikan fungsi neuron yang rusak tersebut[3].Jaringan saraf tiruan (JST) merupakan suatu sistem pemrosesan informasi yang mempunyai karakteristik menyerupai jaringan saraf biologi (JSB). JST tercipta sebagai suatu generalisasi model matematis dari pemahaman manusia (human cognition) yang didasarkan atas asumsi sebagai berikut:

a. Pemrosesan informasi terjadi pada elemen sederhana yang disebut neuron

b. Sinyal mengalir diantara sel saraf/neuron melalui suatu sambungan penghubung.

c. Setiap sambungan penghubung memiliki bobot yang bersesuaian. Bobot ini akan digunakan untuk menggandakan/mengalikan sinyal yang dikirim melaluinya.

d. Setiap sel saraf akan menerapkan fungsi aktivasi terhadap sinyal hasil penjumlahan berbobot yang masuk kepadanya untuk menentukan sinyal keluarannya [4]

Model Struktur neuron Jaringan saraf tiruan dijelaskan pada gambar 1 berikut:

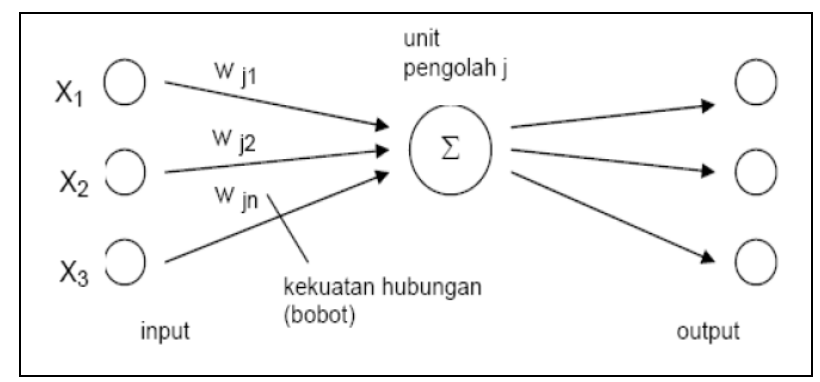

Gambar 1. Model Struktur JST

Jaringan saraf tiruan atau Neural Network dapat belajar dari pengalaman, melakukan generalisasi atascontoh contoh yang diperolehnya dan mengabstraksi karakteristik esensialmasukan bahkan untuk data yang tidak relevan. Algoritma untuk JST beroperasi secara langsung dengan angka sehingga data yang tidak numerik harus diubah menjadi data numerik [4]. 


\subsection{Algoritma Back-propagation}

Propagasi balik atau back-propagation merupakan salah satu teknik pembelajaran/pelatihan supervised learning yang paling banyak digunakan. Metode ini merupakan salah satu metode yang sangat baik dalam menangani masalah pengenalan pola-pola kompleks. Di dalam jaringan propagasi balik, setiap unit yang berada di lapisan input terhubung dengan setiap unit yang ada di lapisan tersembunyi. Setiap unit yang ada di lapisan tersembunyi terhubung dengan setiap unit yang ada di lapisan output. Jaringan ini terdiri dari banyak lapisan (multilayer network). Ketika jaringan diberikan pola masukan sebagai pola pelatihan, maka pola tersebut menuju unit-unit lapisan tersembunyi untuk selanjutnya diteruskan pada unit-unit di lapisan keluaran [5].

Kemudian unit-unit lapisan keluaran akan memberikan respon sebagai keluaran Jaringan saraf tiruan. Saat hasil keluaran tidak sesuai dengan yang diharapkan, maka keluaran akan disebarkan mundur (backward) pada lapisan tersembunyi kemudian dari lapisan tersembunyi menuju lapisan masukan Tahap pelatihan ini merupakan langkah untuk melatih suatu Jaringan saraf tiruan, yaitu dengan cara melakukan perubahan bobot. Sedangkan penyelesaian masalah akan dilakukan jika proses pelatihan tersebut telah selesai, fase ini disebut fase Pengujian [6].

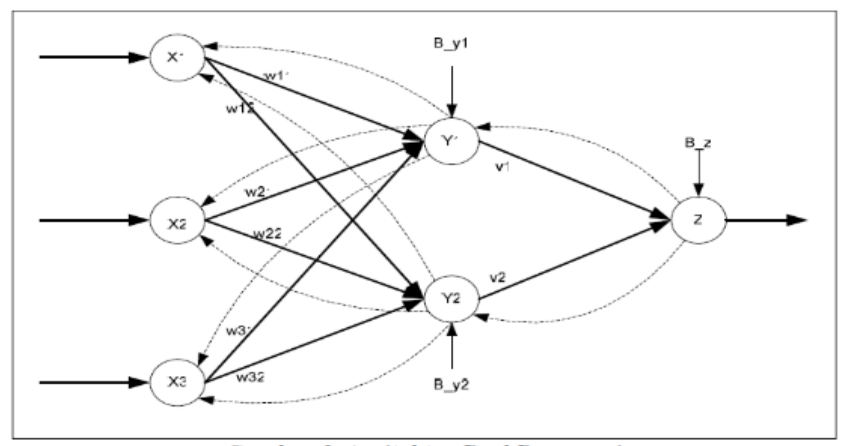

Gambar 2. Algoritma Back-propagation

Back-propagation merupakan model jaringan saraf tiruan dengan layar jamak. Seperti halnya model jaringan saraf tiruan lainnya, back-propagation melatih jaringan untuk mendapatkan keseimbangan antara kemampuan jaringan untuk mengenali pola yang digunakan selama pelatihan serta kemampuan jaringan untuk memberikan respon yang benar terhadap pola masukan yang serupa (tapi tidak sama) dengan pola yang dipakai selama pelatihan [7]

\subsection{Arsitektur Back-propagation}

Back-propagation terdiri dari $n$ buah masukan (ditambah sebuah bias), sebuah layar tersembunyi yang terdiri dari p unit (ditambah sebuah bias), serta $\mathrm{m}$ buah unit keluaran. $W_{\text {oj }}$ dan $I_{0 \mathrm{k}}$ masingmasing adalah bias untuk unit tersembunyi ke-j dan untuk output ke-k. Bias Ioj dan 00k berperilaku seperti bobot dimana output bias ini selalu sama dengan $1 . W_{\mathrm{ij}}$ adalah bobot koneksi antara unit ke-i lapisan input dengan unit ke-j lapisan tersembunyi, sedangkan $\mathrm{W}_{\mathrm{jk}}$ adalah bobot koneksi antara unit kei lapisan tersembunyi dengan unit ke-j lapisan output [8]. 


\subsection{Laba Rugi Komprehensif}

Konsep Laba Komprehensif Tujuan penerapan PSAK menurut Ikatan Akuntan Indonesia (2011) adalah untuk menetapkan dasar-dasar bagi penyajian laporan keuangan bertujuan umum yang selanjutnya disebut laporan keuangan agar dapat dibandingkan baik dengan laporan keuangan periode sebelumnya maupun dengan laporan keungan entittas lain. Pernyataan ini mengatur persyaratan bagi penyajian laporan keuangan, struktur laporan keuangan, dan persyaratan minimum isi laporan keuangan. FASB dalam SFAC No. 3 dan 6 menyebutkan bahwa yang dimaksud dengan laba komprehensif adalah total perubahan aktiva bersih (ekuitas) perusahaan selama satu periode, yang berasal dari semua transaksi dan kegiatan lain dari sumber selain sumber yang berasal dari pemilik. Atau dengan kata lain, laba komprehensif terdiri atas seluruh perubahan aktiva bersih yang berasal dari transaksi operasi. FASB menjelaskan bahwa alasan utama digunakannya istilah laba komprehensif adalah untuk membedakan laba komprehensif dengan laba periode [9]

\subsubsection{Pos Laba Komprehensif}

Pelaporan laba komprehensif adalah pelaporan yang digunakan untuk menyajikan secara total keseluruhan komponen dalam pelaporan ekuitas. Pelaporan ini digunakan untuk melaporkan item-item seperti pendapatan biaya, keuntungan ataupun kerugian yang secara tersendiri dalam prinsip akuntansi berterima umum dimasukkan dalam jenis pelaporan laba komprehensif tetapi dalam penyajian dipihak lain termasuk dalam pos pelaporan net income. Pos laba komprehensif merupakan item yang secara tersendiri langsung ditandingkan kedalam laporan perubahan modal tanpa melalui membandingkan lebih dahulu dalam pelaporan laba rugi [9].

\subsubsection{Komponen Pendapatan Komprehensif Lain}

Pendapatan komprehensif lain adalah total penghasilan dikurangi beban (termasuk penyesuaian reklasifikasi) yang tidak diakui dalam laba rugi sebagaimana yang disyaratkan dalam SAK lainnya [10].

\section{HASIL DAN PEMBAHASAN}

\subsection{Penetapan Masukan (Input) dan Keluaran (Output)}

Data total laba rugi komprehensif selanjutnya akan diolah oleh Jaringan Saraf Tiruan dengan metode Back-propagation. Agar data dapat dikenali oleh Jaringan Saraf Tiruan, maka data harus direpresentasikan ke dalam bentuk numerik antara 0 sampai dengan 1, baik variabel maupun isinya yang merupakan masukan data total laba rugi komprehensif sebagai pengenalan pola dan keluaran yang merupakan prediksi total laba rugi komprehensif yang diperoleh dari model arsitektur terbaik pada saat penentuan pola terbaik. Hal ini dikarenakan jaringan menggunakan fungsi aktivasi sigmoid biner (logsig) yang rangenya dari $0 \mathrm{~s} / \mathrm{d} 1$. Nilai-nilai yang digunakan diperoleh berdasarkan kategori dari masing-masing variabel selain juga untuk memudahkan mengingat dalam pendefinisiannya. 


\subsection{Penetapan Masukan (Input)}

Variabel prediksi total laba rugi komprehensif terdiri dari data total laba rugi komprehensif setiap bulan dengan mengambil data dari Laporan Laba Rugi dan Penghasilan Komprehensif Lain Bulanan nilai. Adapun variabel masukan JST tentang total laba rugi komprehensif terdiri dari :

$\begin{array}{lll}\text { X1 } & = & \text { Total Laba Rugi Bulan Januari } \\ \text { X2 } & = & \text { Total Laba Rugi Bulan Februari } \\ \text { X3 } & = & \text { Total Laba Rugi Bulan Maret } \\ \text { X4 } & = & \text { Total Laba Rugi Bulan April } \\ \text { X5 } & = & \text { Total Laba Rugi Bulan Mei } \\ \text { X6 } & = & \text { Total Laba Rugi Bulan Juni } \\ \text { X7 } & = & \text { Total Laba Rugi Bulan Juli } \\ \text { X8 } & = & \text { Total Laba Rugi Bulan Agustus } \\ \text { X9 } & = & \text { Total Laba Rugi Bulan September } \\ \text { X10 } & = & \text { Total Laba Rugi Bulan Oktober }\end{array}$

\subsubsection{Penetapan Keluaran (Output)}

Adapun penetapan data keluaran adalah data total laba rugi komprehensif 2016. Data ini akan ditransformasi terlebih dahulu dan dirotasi agar keluaran yang diperoleh semakin akurat. Dari proses rotasi didapat 10 pola. Dimana keluaran pola memiliki range $0 \mathrm{~s} / \mathrm{d} 1$ dengan mentranformasikan datanya terlebih dahulu.Adapun variabel keluaran JST tentang total laba rugi komprehensif 2016 terdiri dari:

Hasil yang diinginkan pada tahap ini adalah terdeteksinya suatu nilai untuk penentuan pola arsitektur terbaik dari serangkaian penentuan pola yang dilakukan. Kategorisasi pola terbaik untuk memprediksi total laba rugi komprehensif adalah dengan menentukan tingkat error minimum dari target total laba rugi komprehensif. Semakin kecil error minimun yang dihasilkan suatu target, maka penentuan pola arsitektur terbaik semakin bagus. Untuk penelitian ini nilai error minimun yang terbaik berkisar diantara $0,000-0,001$.

\subsection{Pengolahan Data}

Pengolahan data yang akan dilakukan adalah mengubah data total laba rugi komprehensif 2016 dengan cara mentranformasi data tersebut ke range 0-1 dengan rumus :

$$
x^{\prime}=\frac{0.8(x-a)}{b-a}+0.1
$$

\section{Dimana}

$$
\begin{array}{ll}
\mathrm{x}^{\mathrm{i}} & =\text { Hasil konversi data } \\
\mathrm{x} & =\text { Nilai yang akan dikonversi } \\
\mathrm{a} & =\text { Nilai minimum dari suatu data } \\
\mathrm{b} & =\text { Nilai maksimum dari suatu data } \\
\text { Sehingga diperoleh data sebagai berikut }
\end{array}
$$


Tabel 3. Data Mentah Total Laba Rugi Komprehensif 2016 (Juta)

\begin{tabular}{|c|c|c|c|c|c|}
\hline Aturan & $\mathrm{X} 1$ & $\mathrm{X} 2$ & X3 & $\mathrm{X} 4$ & X5 \\
\hline Pola 1 & Rp1.351.543 & Rp1.990.813 & Rp2.306.110 & Rp586.239 & Rp7.783 \\
\hline Pola 2 & (Rp390.884) & Rp1.351.543 & Rp1.990.813 & Rp2.306.110 & Rp586.239 \\
\hline Pola 3 & Rp796.697 & (Rp390.884) & Rp1.351.543 & Rp1.990.813 & Rp2.306.110 \\
\hline Pola 4 & Rp1.787.979 & Rp796.697 & (Rp390.884) & Rp1.351.543 & Rp1.990.813 \\
\hline Pola 5 & Rp1.219.033 & Rp1.787.979 & Rp796.697 & (Rp390.884) & Rp1.351.543 \\
\hline Pola 6 & Rp2.044.264 & Rp1.219.033 & Rp1.787.979 & Rp796.697 & (Rp390.884) \\
\hline Pola 7 & Rp7.783 & Rp2.044.264 & Rp1.219.033 & Rp1.787.979 & Rp796.697 \\
\hline Pola 8 & Rp586.239 & Rp7.783 & Rp2.044.264 & Rp1.219.033 & Rp1.787.979 \\
\hline Pola 9 & Rp2.306.110 & Rp586.239 & Rp7.783 & Rp2.044.264 & Rp1.219.033 \\
\hline Pola 10 & Rp1.990.813 & Rp2.306.110 & Rp586.239 & Rp7.783 & Rp2.044.264 \\
\hline Aturan & X6 & X7 & X8 & X9 & $\mathrm{X} 10$ \\
\hline Pola 1 & Rp2.044.264 & Rp1.219.033 & Rp1.787.979 & Rp796.697 & $(\mathrm{Rp} 390.884)$ \\
\hline Pola 2 & Rp7.783 & Rp2.044.264 & Rp1.219.033 & Rp1.787.979 & Rp796.697 \\
\hline Pola 3 & Rp586.239 & Rp7.783 & Rp2.044.264 & Rp1.219.033 & Rp1.787.979 \\
\hline Pola 4 & Rp2.306.110 & Rp586.239 & Rp7.783 & Rp2.044.264 & Rp1.219.033 \\
\hline Pola 5 & Rp1.990.813 & Rp2.306.110 & Rp586.239 & Rp7.783 & Rp2.044.264 \\
\hline Pola 6 & Rp1.351.543 & Rp1.990.813 & Rp2.306.110 & Rp586.239 & Rp7.783 \\
\hline Pola 7 & $(\operatorname{Rp} 390.884)$ & Rp1.351.543 & Rp1.990.813 & Rp2.306.110 & Rp586.239 \\
\hline Pola 8 & Rp796.697 & (Rp390.884) & Rp1.351.543 & Rp1.990.813 & Rp2.306.110 \\
\hline Pola 9 & Rp1.787.979 & Rp796.697 & $(\operatorname{Rp} 390.884)$ & Rp1.351.543 & Rp1.990.813 \\
\hline Pola 10 & Rp1.219.033 & Rp1.787.979 & Rp796.697 & $(\mathrm{Rp} 390.884)$ & Rp1.351.543 \\
\hline
\end{tabular}

Pada tabel 3 adalah data mentah total laba rugi komprehensif 2016 yang terdiri dari 10 pola yang dirotasikan. Dari data mentah ini akan ditranformasikan ke range 0-1 dengan rumus (1). Data yang ditransformasi akan menjadi 10 pola dimana data akan diambil 10 pola dan diabagi menjadi 2 bagian. Data bagian pertama terdiri dari pola $1 \mathrm{~s} / \mathrm{d}$ pola 5 sebagai data pelatihan (traning) untuk mendapatkan arsitektur terbaik dari serangkaian arsitektur yang dibuat. Data bagian kedua terdiri dari pola $6 \mathrm{~s} / \mathrm{d}$ pla 10 sebagai data pengujian (testing). Data ini digunakan untuk menguji seakurat mana JST Back-propagation data mengenali data keluaran dari data masukan yang diberikan berdasarkan arsitektur terbaik yang diperoleh pada data pelatihan (traning). Adapun data hasil tranformasi dapat dilihat pada tabel 4 berikut.

Tabel 4. Data Transformasi Total Laba Rugi Komprehensif 2016 (Juta)

\begin{tabular}{cccccc}
\hline Aturan & $\boldsymbol{X 1}$ & $\boldsymbol{X 2}$ & $\boldsymbol{X 3}$ & $\boldsymbol{X 4}$ & $\boldsymbol{X 5}$ \\
\hline Pola 1 & 0,6169 & 0,8065 & 0,9000 & 0,3898 & 0,2183 \\
Pola 2 & 0,1000 & 0,6169 & 0,8065 & 0,9000 & 0,3898 \\
Pola 3 & 0,4523 & 0,1000 & 0,6169 & 0,8065 & 0,9000 \\
Pola 4 & 0,7463 & 0,4523 & 0,1000 & 0,6169 & 0,8065 \\
Pola 5 & 0,5775 & 0,7463 & 0,4523 & 0,1000 & 0,6169 \\
Pola 6 & 0,8223 & 0,5775 & 0,7463 & 0,4523 & 0,1000 \\
Pola 7 & 0,2183 & 0,8223 & 0,5775 & 0,7463 & 0,4523 \\
Pola 8 & 0,3898 & 0,2183 & 0,8223 & 0,5775 & 0,7463 \\
Pola 9 & 0,9000 & 0,3898 & 0,2183 & 0,8223 & 0,5775 \\
Pola 10 & 0,8065 & 0,9000 & 0,3898 & 0,2183 & 0,8223 \\
\hline
\end{tabular}




\begin{tabular}{cccccc}
\hline Aturan & $\boldsymbol{X 6}$ & $\boldsymbol{X 7}$ & $\boldsymbol{X 8}$ & $\boldsymbol{X 9}$ & $\boldsymbol{X 1 0}$ \\
\hline Pola 1 & 0,5775 & 0,7463 & 0,4523 & 0,1000 & 0,5775 \\
Pola 2 & 0,8223 & 0,5775 & 0,7463 & 0,4523 & 0,8223 \\
Pola 3 & 0,2183 & 0,8223 & 0,5775 & 0,7463 & 0,2183 \\
Pola 4 & 0,3898 & 0,2183 & 0,8223 & 0,5775 & 0,3898 \\
Pola 5 & 0,9000 & 0,3898 & 0,2183 & 0,8223 & 0,9000 \\
Pola 6 & 0,8065 & 0,9000 & 0,3898 & 0,2183 & 0,8065 \\
Pola 7 & 0,6169 & 0,8065 & 0,9000 & 0,3898 & 0,6169 \\
Pola 8 & 0,1000 & 0,6169 & 0,8065 & 0,9000 & 0,1000 \\
Pola 9 & 0,4523 & 0,1000 & 0,6169 & 0,8065 & 0,4523 \\
Pola 10 & 0,7463 & 0,4523 & 0,1000 & 0,6169 & 0,7463 \\
\hline
\end{tabular}

\subsection{Perancangan Arsitektur Jaringan Saraf Tiruan}

Jaringan yang digunakan untuk penentuan total laba rugi komprehensif 2016 adalah Jaringan Syaraf Tiruan backpropagation dengan langkah pembelajaran feedforward. Jaringan ini memiliki beberapa lapisan, yaitu lapisan masukan (input), lapisan keluaran (output) dan beberapa lapisan tersembunyi (hidden). Lapisan tersembunyi tersebut membantu jaringan untuk dapat mengenali lebih banyak pola masukan dibandingkan dengan jaringan yang tidak memiliki lapisan tersembunyi. Dengan kata lain sistem yang akan dibuat nantinya memiliki fasilitas dan kemampuan sebagai berikut :

a. Proses Input data pembelajaran untuk JST

b. Proses Pelatihan JST

c. Proses Pengujian dan Prediksi untuk JST

Parameter-parameter dalam pembentukan jaringan backpropagation adalah:

a. 4 neuron (X1,X2 ..., X4) pada lapisan masukan

b. n neuron (Z1,Z2..Zn) pada lapisan tersembunyi

c. 1 neuron (Y1) pada lapisan keluaran Dengan contoh arsitektur 4- n - 1

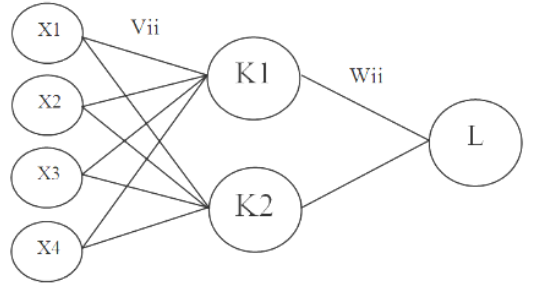

Gambar 3. Arsitektur JST Pada Total Laba Rugi Komprehensif

Jaringan Saraf Tiruan yang akan dibangun adalah algoritma propagasi balik (backpropagation) dengan fungsi aktivasi Sigmoid. Fungsi aktivasi dalam Jaringan Saraf Tiruan dipakai untuk proses perhitungan terhadap nilai aktual output pada hidden layer dan menghitung nilai aktual output pada output layer. 


\subsection{Pemilihan Arsitektur Terbaik Dengan Tools Matlab}

Algoritma pelatihan backpropagation dengan menggunakan 4 input layer, 2 layer tersembunyi, 1 output layer dengan fungsi aktivasi sigmoid biner adalah sebagai berikut :

a. Inisialisasi (initialization), merupakan tahap di mana variabel-variabel nilai akan diset atau didefinisikan terlebih dahulu, misalnya seperti: nilai data input, weight, nilai output yang diharapkan, learning rate dan nilai-nilai data lainnya.

b. Aktivasi (activation),merupakan proses perhitungan terhadap nilai aktual output pada hidden layer dan menghitung nilai actual output pada output layer.

c. Weight Training, merupakan proses perhitungan nilai error gradient pada output layer dan menghitung nilai error gradient pada hidden layer

d. Iteration, merupakan tahap akhir dalam penggujian, dimana jika masih terjadi error minimum yang diharapkan belum ditemukan maka kembali pada tahap aktivasi (activation).

Berdasarkan hasil pelatihan dan pengujian dengan menggunakan 4 model arsitektur pada algoritma backpropogation yakni: 4-25-1; 4-50-1; 4-50-75-1 dan 4100-1, diperoleh model arsitektur 4-50-1 adalah yang terbaik dengan hasil akurasi prediksi $80 \%$. Berikut ini parameter matlab yang digunakan untuk menentukan model arsitektur terbaik

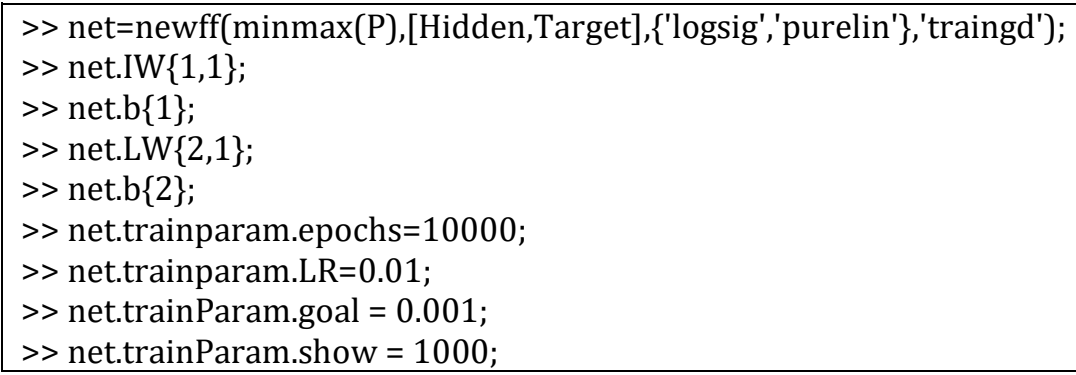

Berdasarkan parameter tersebut, proses penentuan model arsitektur terbaik dengan menggunakan backpropogation dilakukan. Berikut ini hasil pelatihan arsitektur 4-50-1 dengan tools matlab.

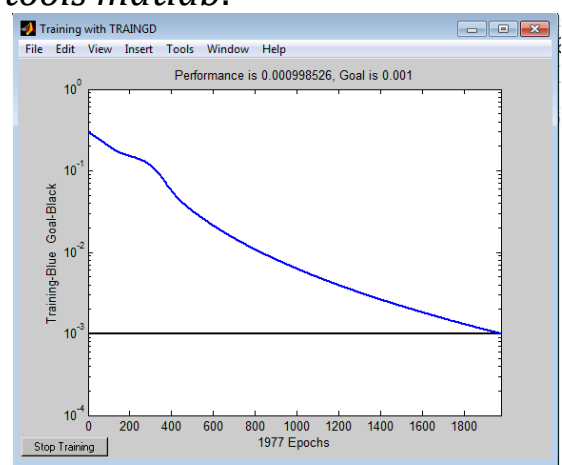

Gambar 4. Hasil Epoch Training Dengan Arsitektur 4-50-1 
Pada gambar 4 dapat dijelaskan bahwa Epoch training = 1977 dan Mean Square Error (MSE) sebesar 0,000997867 untuk mencapai goal yang diinginkan. Berikut ini hasil data pelatihan dan pengujian untuk arsitektur 4-50-1 seperti pada tabel 5 dan 6 berikut

Tabel 5. Pelatihan arsitektur 4-50-1

\begin{tabular}{llllll}
\hline \multirow{2}{*}{ No } & \multirow{2}{*}{ Real } & \multirow{2}{*}{ Target } & \multicolumn{4}{l}{ ANN 4-50-1 } \\
\cline { 4 - 6 } & & & Output & Error & SSE \\
\hline 1 & Pola 1 & 0,1000 & 0,1079 & $-0,008$ & 0,0000624100 \\
2 & Pola 2 & 0,1230 & 0,1583 & $-0,035$ & 0,0012459810 \\
3 & Pola 3 & 0,1422 & 0,1664 & $-0,024$ & 0,0005849103 \\
4 & Pola 4 & 0,1517 & 0,1647 & $-0,013$ & 0,0001692219 \\
5 & Pola 5 & 0,9000 & 0,8459 & 0,054 & 0,0029268100 \\
\hline & & & & Total & 0,0049893332 \\
& & & & MSE & 0,0009978666 \\
\hline
\end{tabular}

Tabel 6. Pengujian arsitektur 4-50-1

\begin{tabular}{|c|c|c|c|c|c|c|}
\hline \multirow{2}{*}{ No } & \multirow{2}{*}{ Real } & \multirow{2}{*}{ Target } & \multicolumn{4}{|c|}{ ANN 4-50-1 } \\
\hline & & & Output & Error & SSE & Hasil \\
\hline 1 & Pola 6 & 0,4099 & 0,5073 & $-0,097$ & 0,0094842982 & Benar \\
\hline 2 & Pola 7 & 0,1000 & 0,1035 & $-0,003$ & 0,0000122500 & Benar \\
\hline 3 & Pola 8 & 0,9000 & 0,0781 & 0,822 & 0,6755196100 & Salah \\
\hline 4 & Pola 9 & 0,5758 & 0,5802 & $-0,004$ & 0,0000191775 & Benar \\
\hline \multirow[t]{2}{*}{5} & Pola 10 & 0,7993 & 0,7825 & 0,017 & 0,0002829935 & Benar \\
\hline & & & & $\begin{array}{l}\text { Total } \\
\text { MSE }\end{array}$ & $\begin{array}{l}0,6853183291 \\
0,1370636658\end{array}$ & $80 \%$ \\
\hline
\end{tabular}

Berdasarkan tabel 6, tingkat akurasi kebenaran pada pengujian model arsitektur 4-50-1 adalah 80\%.

\section{SIMPULAN}

Berdasarkan hasil dan pembahasan diatas, maka penulis dapat mengambil kesimpulan sebagai berikut:

a. Menambahkan banyak hidden layer pada saat pelatihan dan pengujian, bukan merupakan suatu hasil yang maksimal. Hal ini terbukti pada model arsitektur 450-75-1 dengan Mean Square Error (MSE) pengujian=0,0009981215, Epoch pelatihan $=538$ dan tingkat akurasi kebenaran hanya $20 \%$.

b. Setelah dilakukan percobaan dalam proses pelatihan dan pengujian sistem yang dilakukan dengan menggunakan software aplikasi Matlab 6.1, diperoleh hasil 450-1 merupakan model arsitektur terbaik dengan Mean Square Error (MSE) sebesar 0,000997867.

c. Dari model arsitektur yang terpilih, hal ini dapat dilanjutkan keproses prediksi untuk mengetahui akurasi berdasarkan data yang sudah diperoleh.

d. Untuk meningkatkan tingkat akurasi maka dibutuhkan data pelatihan yang lebih kompleks dengan memberikan lebih banyak model arsitektur.

\section{UCAPAN TERIMA KASIH}

Ucapan terima kasih kami sampaikan kepada Direktorat Riset dan Pengabdian Masyarakat Direktorat Jenderal Penguatan Riset dan Pengembangan 
Kementerian Riset, Teknologi dan Pendidikan Tinggi atas pendanaan Penelitian Dosen Pemula (PDP) tahun pelaksanaan 2018

\section{DAFTAR PUSTAKA}

[1] D. Kurnianingtyas, B. A. Rahardian, D. P. Mahardika, A. K. A, and K. Angraeni, "Sistem Pendukung Keputusan Diagnosis Penyakit Sapi Potong Menggunakan K- Nearest Neighbour (K- NN)," Jutnal Teknol. Inf. dan Ilmu Komput., vol. 4, no. 2, pp. 122-126, 2017.

[2] Agus Perdana Windarto, "Implementasi Jst Dalam Menentukan Kelayakan Nasabah Pinjaman KUR Pada Bank Mandiri Mikro Serbelawan Dengan Metode Backpropogation," J-SAKTI Jurnal Sains Komput. dan Inform., vol. 1, no. 1, pp. 12-23, 2017.

[3] A. P. Windarto, "Implementation of Data Mining on Rice Imports by Major Country of Origin Using Algorithm Using K-Means Clustering Method," Int. J. Artif. Intell. Res., vol. 1, no. 2, pp. 26-33, 2017.

[4] Wuryandari and Afrianto, "Perbandingan Metode Jaringan Syaraf Tiruan Backpropogation dengan Learning Vector Quantization pada pengenalan wajah," J. KOMPUTA, vol. 11, no. 1, p. 2012, 2012.

[5] Solikhun, A. P. Windarto, Handrizal, and M.Fauzan, "Jaringan Saraf Tiruan Dalam Memprediksi Sukuk Negara Ritel Berdasarkan Kelompok Profesi Dengan Backpropogation Dalam Mendorong Laju Pertumbuhan Ekonomi," Kumpul. J. Ilmu Komput., vol. 4, no. 2, pp. 184-197, 2017.

[6] A. Gupta and M. Shreevastava, "Medical Diagnosis using Back propagation Algorithm," Int. J. Emerg. Technol. Adv. Eng., vol. 1, no. 1, pp. 55-58, 2011.

[7] D. O. (Faculty of I. E.-G. U. Maru'ao, "Neural Network Implementation in Foreign Exchange Kurs Prediction," 2010.

[8] Sumijan, A. P. Windarto, A. Muhammad, and Budiharjo, "Implementation of Neural Networks in Predicting the Understanding Level of Students Subject," Int. J. Softw. Eng. Its Appl., vol. 10, no. 10, pp. 189-204, 2016.

[9] R. P. S. Wahyu and S. Praptoyo, "Penyajian dan komponen other comprehensive income," J. Ilmu Ris. Akunt., vol. 3, no. 12, p. 2014, 2014.

[10] A. Eliza, "Penyajian Laporan Keuangan dan Perbedaannya dengan PSAK No.1 (Revisi 1998)-Tinjauan Atas PSAK No.1 (Revisi 2009)," J. Ilm. ESAI, vol. 6, no. 2, 2012. 